\title{
SOLVING PROBLEMS IN STEREOLOGY WITHOUT MATHEMATICAL FORMALISM
}

\author{
LESZEK WOJNAR \\ Institute of Applied Informatics, Cracow University of Technology, Al. Jana Pawła II 37, 31-864 Cracow, \\ Poland \\ e-mail: leszek.wojnar@mech.pk.edu.pl, leszek.wojnar@gmail.com \\ (Received March 13, 2018; accepted April 22, 2018)
}

\begin{abstract}
Scientific work is often very time consuming and the results are frequently not clear for the audience. A sense of humour is a good tool for demonstration of complicated problems. The paper describes selected cases from the past 30 years in which a sense of humour together with appropriate cartoons were successfully applied.
\end{abstract}

Keywords: cartoons, history, humour, stereology

\section{INTRODUCTION}

This is an unusual paper as it neither reviews several publications nor describes any purely scientific problem. It is devoted to the application of cartoons and a sense of humour in solving various problems. However, no consistent method or idea related to cartoons is presented here, so this work is also insufficient for publication in any journal related to the International Society for Humour Studies. This paper just documents some of the history and achievements of the International Society for Stereology and Image Analysis (ISSIA) in an unusual way - through the use of humorous cartoons for commenting on events, works, and people.

My dealings with ISSIA (formerly the International Society for Stereology, ISS) started in the 1980s. At that time ISS distributed T-shirts with the ISS logo surrounded by the following sentence: STEREOLOGISTS DO IT FROM ALL POSSIBLE ANGLES. This makes it clear that not only measurements can be done from different angles. My first cartoons related to stereology were presented during the $7^{\text {th }}$ International Congress of ISS in Caen, 1987 (Wojnar, 2002).

\section{CASE HISTORIES}

Almost thirty years ago, in October 1990, the inter-national STERMAT conference (STEreology in MATerials) was held in Szczyrk, Poland ${ }^{1}$. The con-

\footnotetext{
${ }^{1}$ The description of this single case is copied from Wojnar (2016)
}

ference was devoted, among other issues, to methods of image analysis. Foreign guests came from Czechoslovakia, France, Japan, Switzerland, the United States, Great Britain, the Soviet Union and also the German Democratic Republic and the Federal Republic of Germany. Coincidentally, on the second day of the conference, German reunification took place. Our German guests, now it seems to be quite obvious, were very happy about it and decided to invite everybody for a glass of champagne. Among us Poles the atmosphere got gloomy - there were a number of people who still remembered the Second World War and whose families suffered a lot under the German occupation. Jean-Luis Chermant, the President of ISS, came up to me and said: "Leszek, we have to do something, the situation is extremely edgy and tense."

Without hesitation, I sketched a set of drawings which Jean-Luis then used for his presentation. The first drawing was entitled the ORIGINAL and presented the border line of the current territory of six countries: Austria, Czechoslovakia, the German Democratic Republic, Poland, the Federal Republic of Germany, and Hungary (Fig. 1).

The second drawing, which showed the frontier between the eastern and western blocs, was named the ORIGINAL + SKIZ (Fig. 1). It made an allusion to the political situation as SKIZ is the abbreviation of Skeleton by Influence Zone. Of course, the audience instantly understood the hidden meaning and laughter could be heard. 

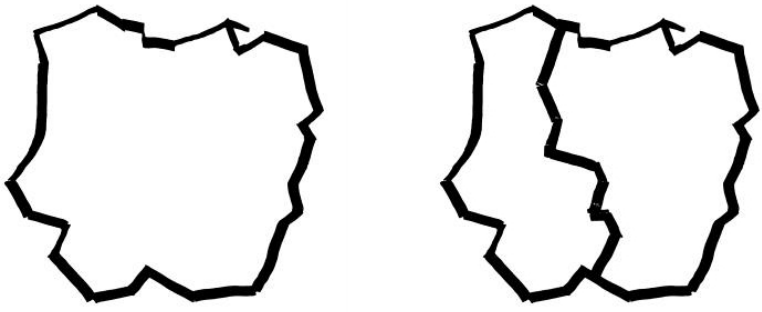

Fig. 1. The two initial drawings commenting on the reunification of Germany. Details in the text.

The next cartoon illustrated the result of the SEGMENTATION, i.e., the particular borders of each of the countries. Jean-Luis interpreted this as such: "the changes on the map correspond with commonly used image analysis transformations and no one should bother about it" (Fig. 2). The analogy was then confirmed by the next picture showing the GEODESIC PATH, which was explained as "the shortest way to overcome obstacles" (Fig. 2). That was exactly the way, through Czechoslovakia and Austria, which the refugees from the German Democratic Germany chose for their escape route. That association also caused general amusement.

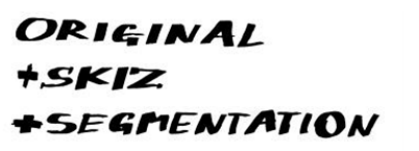

\section{GEODESIC PATH}
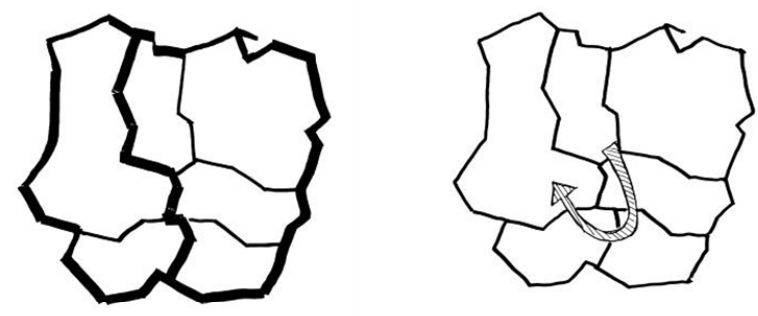

Fig. 2. The next cartoons commenting on the reunification of Germany. Details in the text.

At the end of his speech Jean-Luis showed the final result of image transformation - a map of reunified Germany - and concluded: "to do a successful image analysis, especially for morphological transformations, proper structuring elements need to be chosen" (Fig. 3).
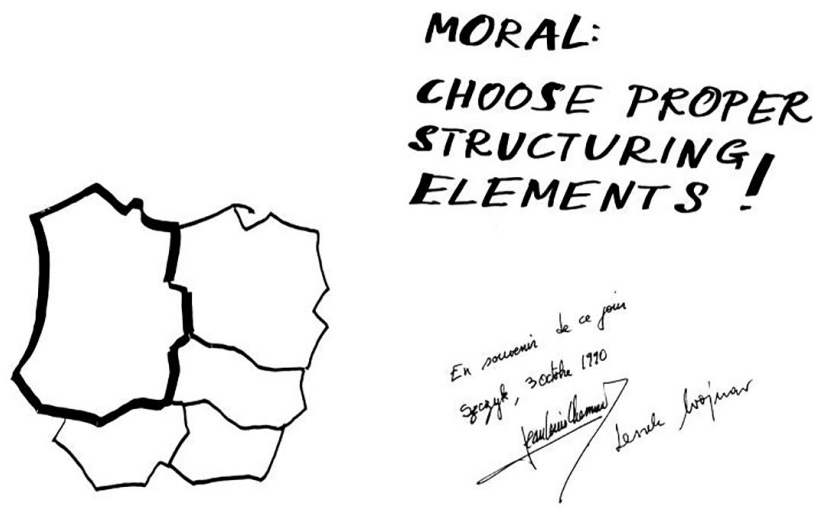

Fig. 3. The final cartoons dedicated to the reunification of Germany. Details in the text.

The round of applause was the first sign that the crisis was over. The champagne was drunk and a friendly atmosphere prevailed to the very end of the conference. Today, after more than a quarter of century, some people find it difficult to understand what an awkward situation we managed to defuse by "taming" the problem with some humour (Wojnar, 2002, 2016). The event described above had another consequence - I began to make use of humorous drawings much more often.

Scientists use increasingly sophisticated and extremely expensive apparatus that requires highly qualified personnel for operation. To make things worse, interpretation of results obtained from sophisticated systems is often difficult and uncertain. In many cases good results can be achieved using less complicated apparatus if one prepares an appropriate research concept and well-designed experiments. Unfortunately, it is considered impolite to criticize overuse of highend scientific tools. Nevertheless, it can be quite easily done if only an appropriate series of humorous cartoons is presented (Fig. 4).

Quite often humorous drawings are inspired by the current situation. Such cartoons can be difficult if not impossible to understand without additional comments. For example, at the $8^{\text {th }}$ European Congress on Stereology and Image Analysis in Bordeaux 2001, the conference was guarded in the evenings by men with dogs. During the sessions, the spatial resolution of modern stereological methods was discussed, as well as the advantages and rules of random sampling. The resulting cartoon (Fig. 5), however, can be presented even without explanation of the conditions under which it was drawn (Wojnar, 2002). 


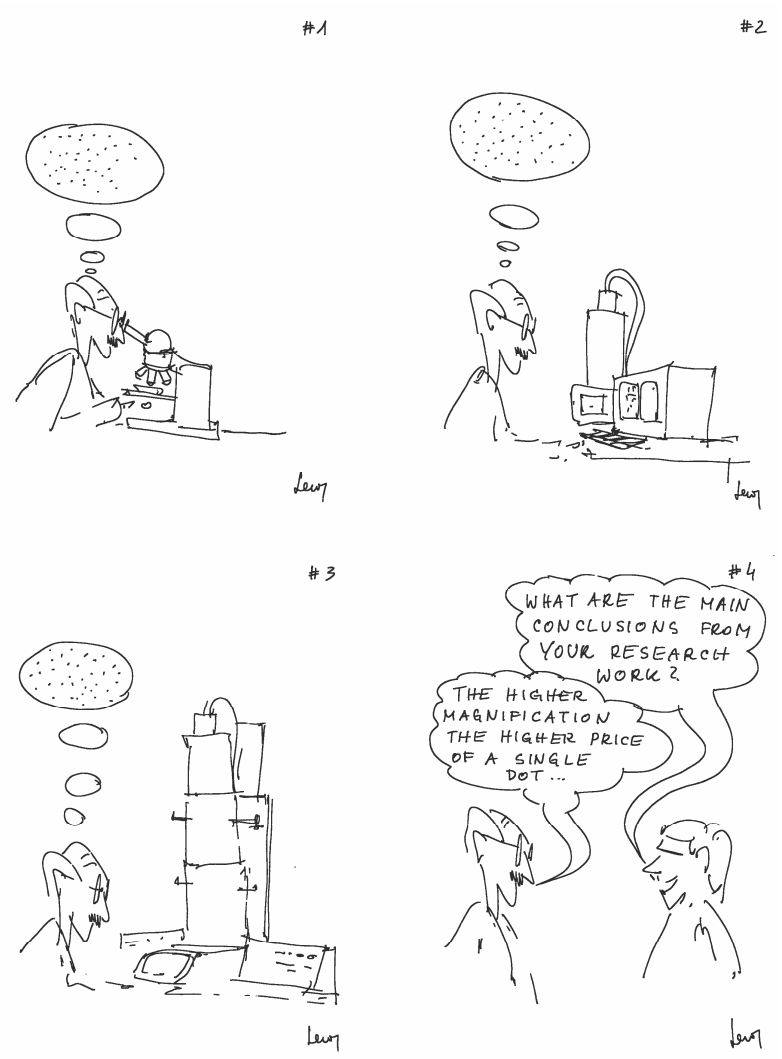

Fig. 4. Application of very expensive apparatus does not assure good results.

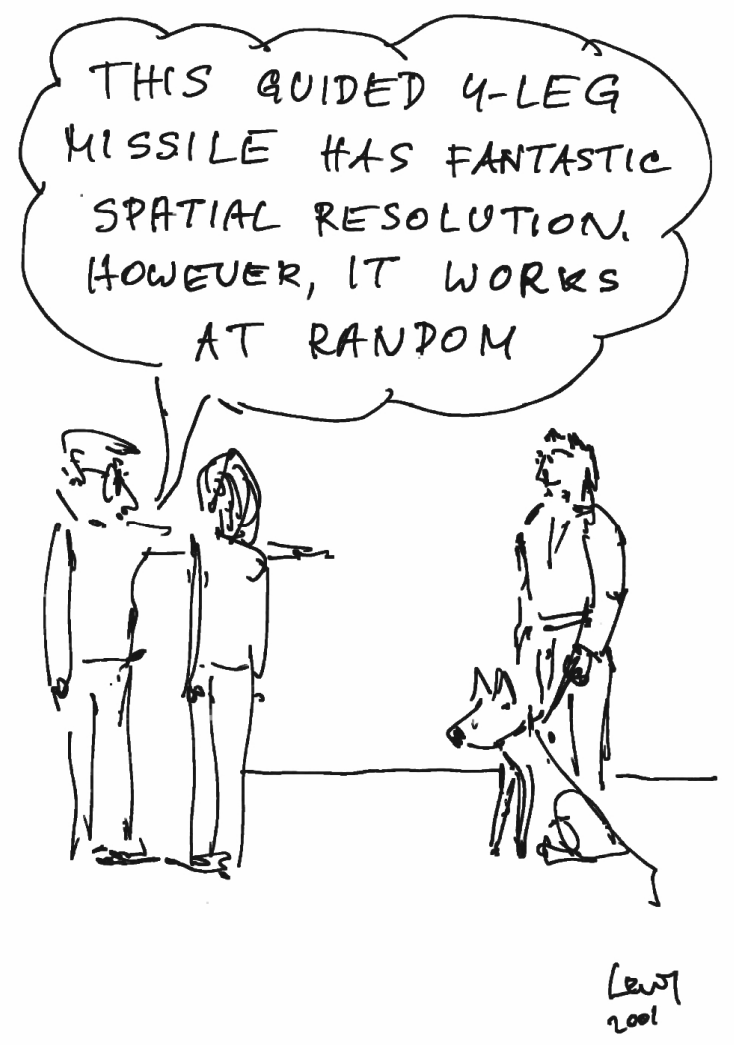

Fig. 5. This cartoon is quite universal even if it was drawn in response to a specific situation at a conference.
Almost all the STERMAT conferences have been held in the Polish mountains. The consequences are twofold. First, the conference venue is not easily accessible and requires organisation of additional transportation. On the other hand, the conference can be cheaper and accommodation of all the participants in the same place promotes personal contact and discussion. In this case the double meaning of the phrase "high level of sessions" enables a humorous explanation of why the conference was held in the mountains (Fig. 6).

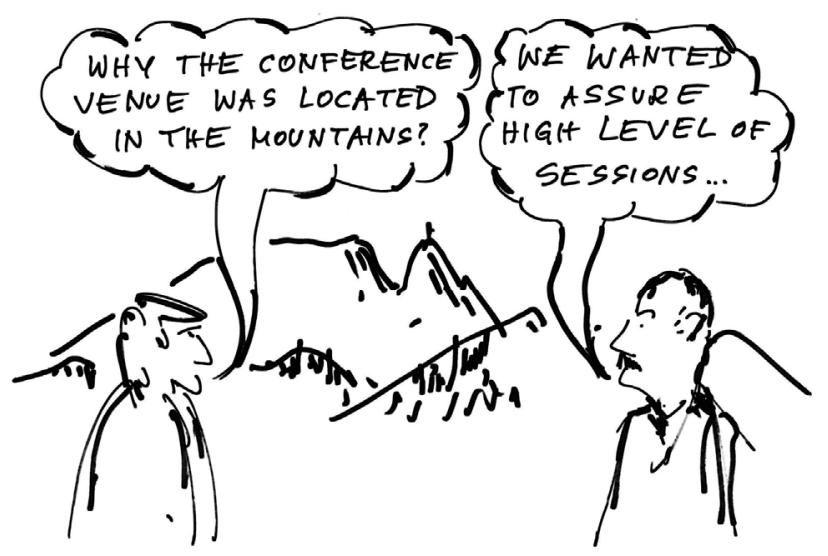

Fig. 6. STERMAT conferences are traditionally held in the mountains.

Many speeches are long and extremely boring. Sometimes, one hears that a short speech is a good speech. This can be really true as using spoken English is often a big challenge for the speaker. In the case of the STERMAT series, one of the people who opens the conference has been participating in this series for 25 years. Combining these two facts resulted in a quite clever cartoon (Fig. 7) that was used during the closing ceremony.

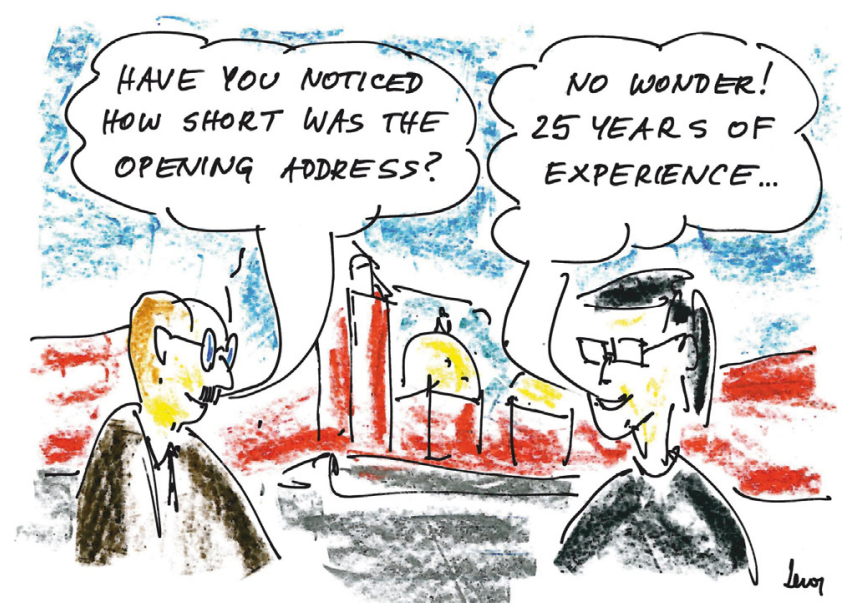

Fig. 7. A short speech is a good speech, isn't it?

Fig. 4 illustrates the problem of overuse of expensive, sophisticated apparatus. One should notice, 
however, that there is also very compact, multipurpose equipment that is simple to operate and can be successfully applied in a wide range of research. An excellent example of such equipment is a table scanning microscope made by Hitachi. It is not nice if one has to conclude that it is still too expensive. So, we can show a sense of humour by saying that this relatively inexpensive instrument, with a very good value-to-price ratio, is simply too big for us (Fig. 8).

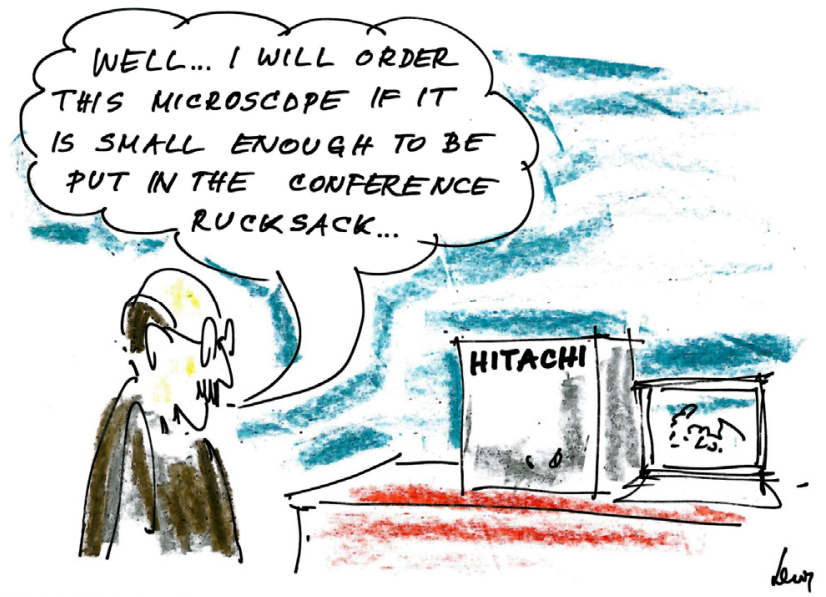

Fig. 8. The real problem is not size but money.

During the $9^{\text {th }}$ STERMAT conference, which was held in 2012 in Zakopane (Poland), an excursion to the Pieniny mountains was organized. A well-known attraction in this region is rafting through the Pisturesque Dunajec River Gorge. The almost vertical white rocks on both sides of the gorge mean it is difficult to guess the direction of the next turn. Simultaneously, the landscape is often very impressive, even breathtaking. This experience inspired the cartoon shown in Fig. 9, which is related to a very common problem in complex visual data analysis: it can be very difficult to interpret a series of images.

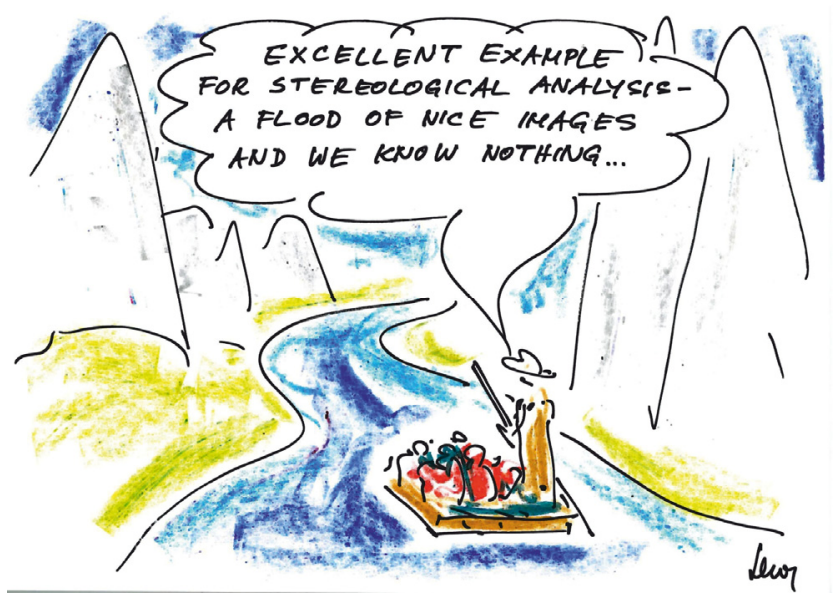

Fig. 9. Rafting on the Dunajec River Gorge. Details in the text.
It is quite difficult to find young scientists interested in the development and application of stereological methods. Therefore, in order to attract them, a Young Stereologists Session used to be arranged at conferences. It was discussed many times what the role of experienced stereologists should be in the preparation of papers or oral presentations. One of the questions was whether an experienced scientist should be listed as a co-author of the work. It is obvious that this problem is practically unsolvable. Adding the name of the supervisor to the list of authors does not show that the role of the young scientists is only marginal. On the other hand, the lack of the supervisor's name also does not prove that the young scientist prepared the work independently. Discussions on this topic were long and very serious. In order to release the atmosphere, an appropriate cartoon was prepared and successfully applied (Fig. 10).

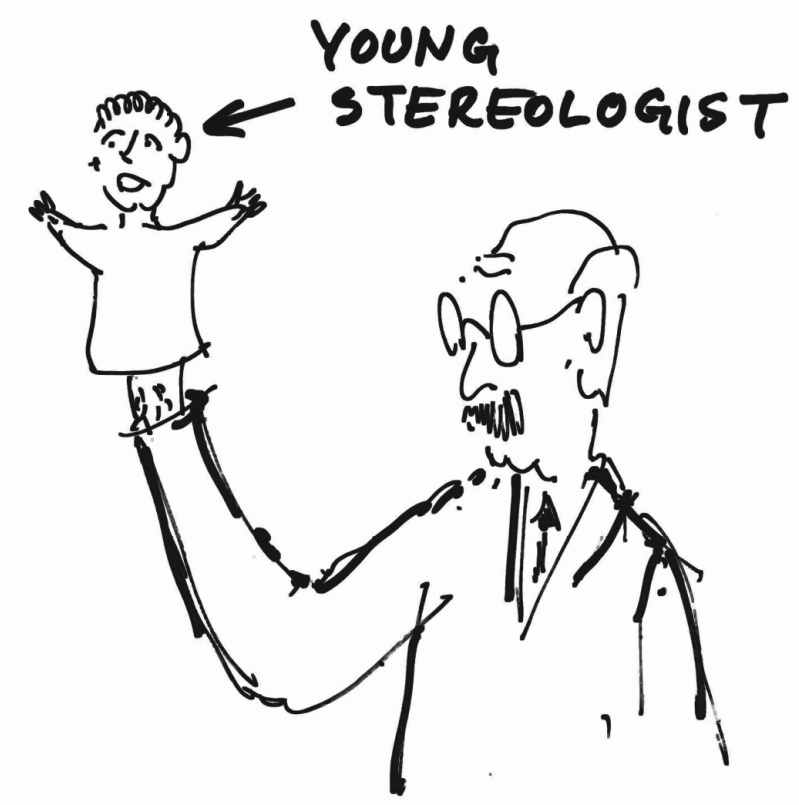

Fig. 10. Discussions on the role of supervisor are endless. Probably, this problem is universal and not related only to stereology.

And now we reach a weak point of our Society. In spite of the young stereologists' competition and other initiatives, our society lacks new and young members. This problem is not new and nobody knows how to solve it. Once more, solving this problem is not easy but with the help of an appropriate cartoon one can give a good argument to provoke and start serious discussion (Fig. 11). 


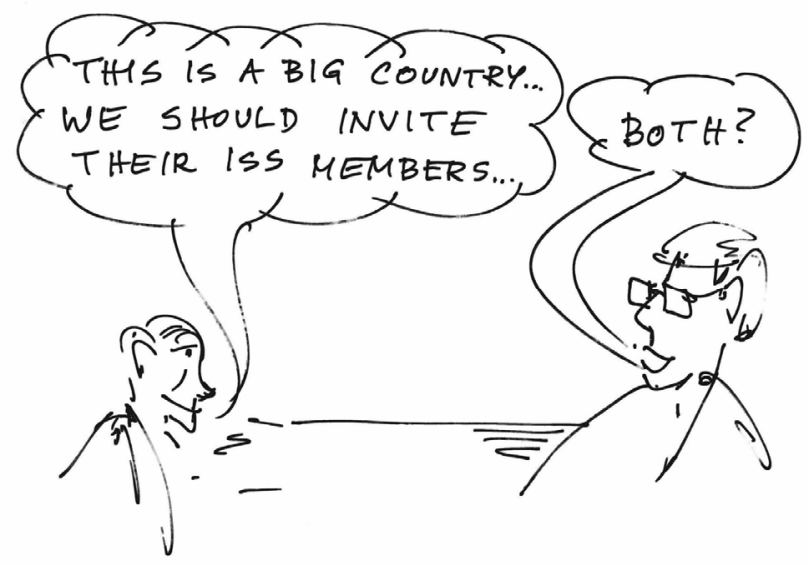

Fig. 11. The problem of membership has a long history.

An appropriate sampling strategy is a key problem in stereology. Depending on the structure to be analysed, the applied methods, and the technical limitations, one can apply random, systematic, or mixed sampling. The organizers of conferences usually try to assure a good quantity of high quality food, especially for the official conference dinner. Sometimes, so many dishes, fruits, cakes, or drinks are available that it is difficult to choose. This is an excellent occasion to recall the problems of choosing proper sampling for stereological examination (Fig. 12).

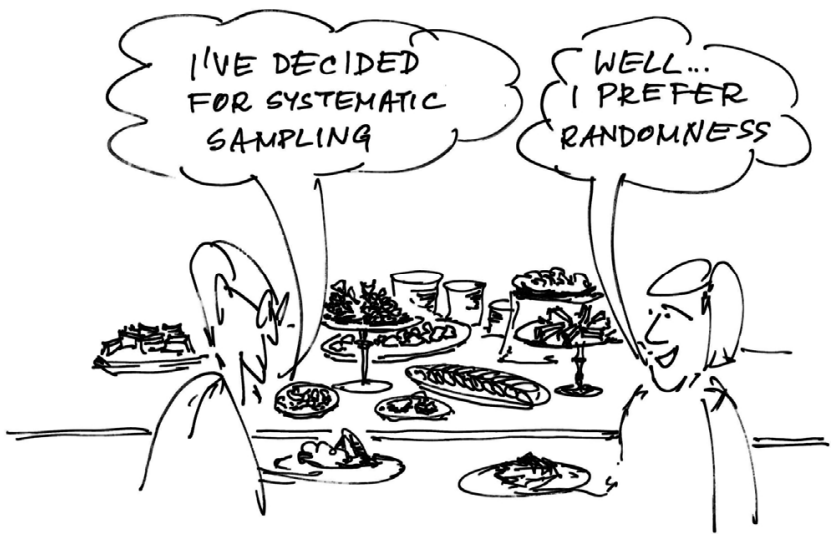

Fig. 12. Discussions on the advantages of random over systematic sampling are endless.

At the $9^{\text {th }}$ European Congress on Stereology and Image Analysis in Zakopane, Poland in 2005, some discussions were very complex and almost every speaker was asked numerous questions, some of which were very difficult to answer. Therefore, in order to help answer them, additional comments were quite often added. At one point, when the discussion became heated, one of the participants said; "Please, stop these negative questions". The atmosphere cooled slightly and this incident inspired me to prepare an appropriate classification of questions for the closing session (Fig. 13).

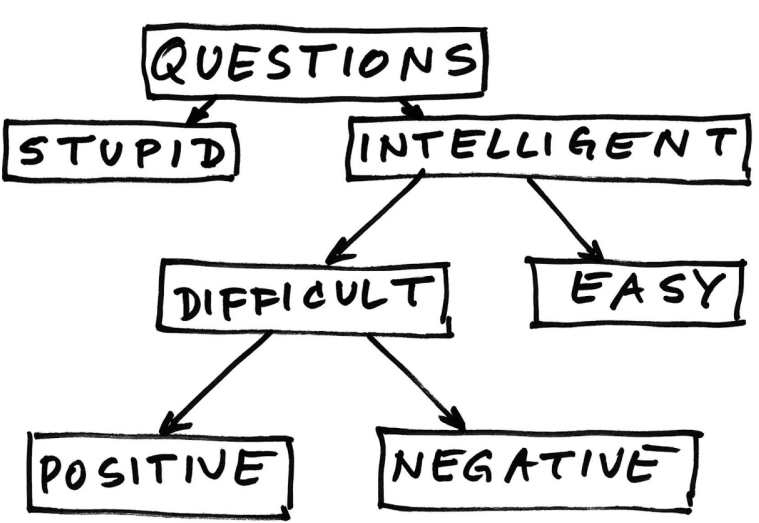

Fig. 13. Humorous classification of questions. Details in the text.

Obviously, scientists need money for research, and to significantly improve their chances of securing funding it helps if they are highly rated according to several academic metrics. Unfortunately, these rankings do not reflect the quality of work, but rather various bibliometric parameters such as the number of published papers and citations, the Hirsch index or impact factor. Consequently, scientists are forced to publish more and more papers. Conferences are a good way to publish relatively quickly, but many participants are not interested in oral presentations. This can be explained by a remark I heard some years ago: when you have to present something in a language that is not your native one, you lose $50 \%$ of your intelligence. One of the consequences of this reluctance is the growing number of posters. Once more, straightforward discussion on this problem can be difficult but, as usual, we can use an appropriate cartoon (Fig. 14).

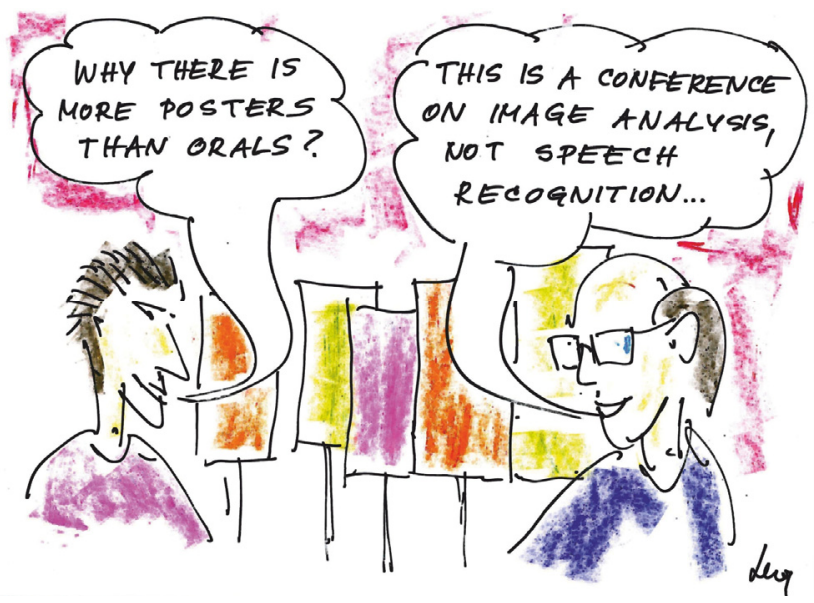

Fig. 14. Funny and obviously false interpretation of the falling ratio of oral presentations.

The lack of sufficient funds for research and related activities is universal all over the world. In the European Community scientists can apply for addi- 
tional money through various competitive grant systems. Unfortunately, the use of grant money requires appropriate documentation. This documentation becomes more and more complicated and some regulations are considered totally unnecessary, if not stupid. Nevertheless, the bureaucracy grows and errors in documentation can result in the loss of money. This problem was illustrated by an appropriate cartoon (Fig. 15). The text in the cloud is in Polish in order to keep the original graphics, but it is translated in the caption.

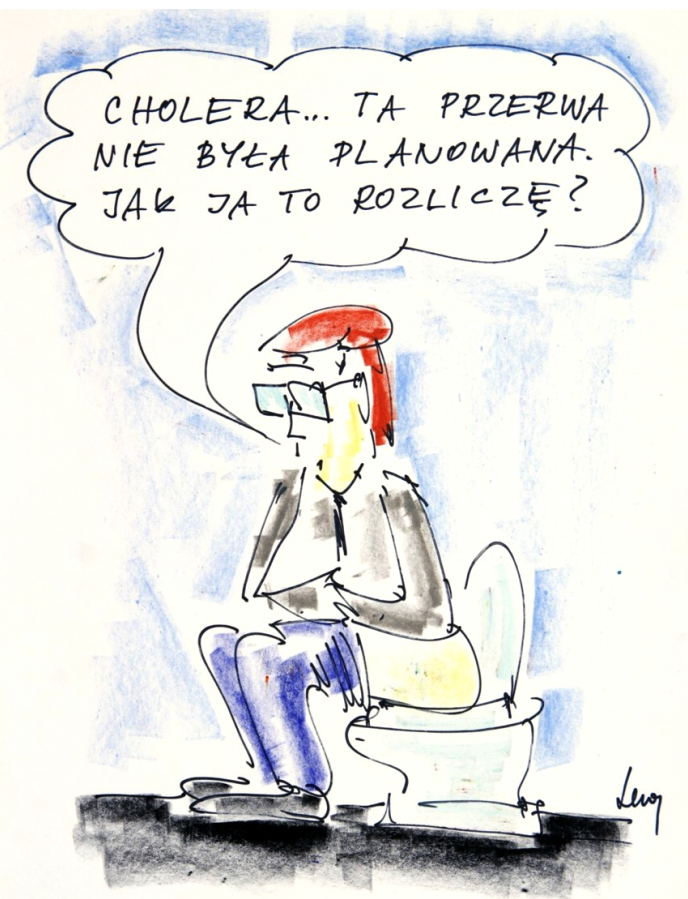

Fig. 15. Oh, gosh... This break was not planned. How will I add it to the report?

\section{DISCUSSION}

This short review is based on a collection of cartoons created over the last 30 years and contains less than $10 \%$ of the total number of drawings.

The examples presented in this paper show that laughter constitutes a risky yet effective weapon. A comedic element might not only lighten the mood, but also allows difficult matters to be dealt with successfully. A deadly serious approach may evoke a negative reaction, whereas a laughable form seems to be easily accepted. The reason is that hardly anybody wants to be perceived as a person without a sense of humour.

Being a clown is not easy, especially if you are highly regarded in your field. On one hand, you have to be careful not to be too cutting, but on the other, polite satire is like a cat in gloves which catches no mice.

\section{REFERENCES}

Chermant JL, Wojnar L (1992). Image analysis and related techniques: who is not interested? Acta Stereol 11/ Suppl 1: 15-37.

Wojnar L (2002). Stereology from one of all the possible angles. Image Anal Stereol 21(Suppl 1): S1-S11.

Wojnar L (2016). Kreski - Sketches. Cracow: Cracow University of Technology, (1-119). 